\title{
Rice and noodle consumption is associated with insulin resistance and hyperglycaemia in an Asian population
}

\author{
Yasmin L. M. Zuñiga ${ }^{1}$, Salome A. Rebello ${ }^{2 *}$, Puay Leng $\mathrm{Oi}^{2}$, Huili Zheng ${ }^{2}$, Jeannette Lee $^{2}$, \\ E. Shyong $\mathrm{Tai}^{3}$ and Rob M. Van Dam ${ }^{2,3,4}$ \\ ${ }^{1}$ Division of Endocrinology, Department of Medicine, National University Hospital, 1E Kent Ridge Road, NUHS Tower Block \\ Level 10, Singapore 119228, Singapore \\ ${ }^{2}$ Saw Swee Hock School of Public Health, National University of Singapore, National University Health System, Block MD3, \\ \#03-17, 16 Medical Drive, Singapore 117597, Singapore \\ ${ }^{3}$ Department of Medicine, Yong Loo Lin School of Medicine, National University of Singapore, National University Health \\ System, 1E Kent Ridge Road, NUHS Tower Block Level 10, Singapore 119228, Singapore \\ ${ }^{4}$ Department of Nutrition, Harvard School of Public Health, Boston, MA 02115, USA
}

(Submitted 5 March 2013 - Accepted 30 September 2013 - First published online 14 November 2013)

\begin{abstract}
High consumption of refined grains, particularly white rice, has been reported to be associated with a higher risk of type 2 diabetes. Therefore, in the present study, we evaluated the association between rice and noodle consumption and markers of glucose homeostasis, inflammation and dyslipidaemia in an Asian population. We carried out a population-based cross-sectional study in 2728 Singaporean Chinese men and women aged between 24 and 92 years. Rice and noodle intake was assessed using a validated FFQ and studied in relation to glycaemic (fasting glucose, glycated $\mathrm{Hb}$, homeostasis model assessment (HOMA) index for insulin resistance (HOMA-IR) and HOMA index for $\beta$-cell function (HOMA- $\beta$ )), inflammatory (plasma adiponectin and C-reactive protein (CRP)) and lipid (fasting TAG and HDL-cholesterol (HDL-C)) markers. We used multiple linear regression analyses with adjustment for total energy intake and sociodemographic, anthropometric (BMI and waist:hip ratio) and lifestyle factors. Higher rice consumption was found to be associated with higher fasting glucose concentrations ( $0.81 \%$ higher values per portion increment; 95\% CI 0.09, 1.54) and HOMA-IR (4.62\%; 95\% CI $1.29,8.07)$. Higher noodle consumption was also found to be significantly associated with higher fasting glucose concentrations (1.67\%; 95\% CI 0.44, 2.92), HOMA-IR (6.17\%; 95\% CI 0.49, 12.16) and fasting TAG concentrations (9.17\%; $95 \%$ CI 3.44, 15.22). No significant association was observed between rice and noodle consumption and adiponectin, CRP and HDL-C concentrations or HOMA- $\beta$ in the fully adjusted model. These results suggest that high consumption of rice and noodles may contribute to hyperglycaemia through greater insulin resistance and that this relationship is independent of adiposity and systemic inflammation.
\end{abstract}

Key words: Carbohydrates: Glucose metabolism: Inflammation: Cholesterol: Adiponectin: C-reactive protein

More than half of all individuals with diabetes mellitus in the world reside in Asia, and a large increase in the number of diabetes cases has been predicted for this continent ${ }^{(1)}$. Grains in the form of rice and noodles are the primary carbohydrate source for most Asian populations, with rice providing as much as $60 \%$ of total energy in Southeast Asia ${ }^{(2,3)}$. Rice and other grains are predominantly consumed as refined grains by most Asian populations ${ }^{(4,5)}$. Accounts as to when polished rice started being consumed in Asia are limited; in Japan, consumption of polished white rice began at the end of the seventeenth century and was initially limited to the urban upper class due to its high price ${ }^{(6)}$. Currently, mechanised steel roller mills and automated sifting devices are being used to efficiently refine grains, resulting in a huge loss of vitamins, minerals, essential fatty acids and phytochemicals ${ }^{(4,7,8)}$.

Recently published data suggest that there is an association between high white rice consumption and a higher risk of type 2 diabetes in both Western ${ }^{(9)}$ and Asian ${ }^{(10-12)}$ populations. However, the biological mechanisms that may underlie this association are unclear. In addition, data on the association between consumption of noodles, another major source of refined grains in Asia, and risk of type 2 diabetes

Abbreviations: CRP, C-reactive protein; FPG, fasting plasma glucose; HDL-C, HDL-cholesterol; HOMA, homeostasis model assessment; HOMA- $\beta$, homeostasis model assessment of $\beta$-cell function; HOMA-IR, homeostasis model assessment of insulin resistance; SP2, Singapore Prospective Study Program-2.

*Corresponding author: S. A. Rebello, fax +65 67791489, email ephsar@nus.edu.sg 
are sparse ${ }^{(11)}$. High consumption of white rice and noodles may lead to high dietary glycaemic index ${ }^{(13)}$ and glycaemic load, which have been suggested to increase the risk of type 2 diabetes through excess postprandial variations in blood glucose and insulin concentrations ${ }^{(14-19)}$. Such variations in insulin concentrations may increase circulating NEFA concentrations ${ }^{(20)}$ and reduce the number of insulin receptors, both of which can contribute to insulin resistance ${ }^{(21)}$. Furthermore, in contrast to whole grains, refined grains contain less amounts of fibre and phytochemicals that may lower the risk of type 2 diabetes ${ }^{(11,18,19,22-24)}$. Studies on the association between refined grain consumption and metabolic risk factors can provide insights into the potential mechanisms that may contribute to a higher risk of type 2 diabetes. However, few of these studies have been carried out in Asian populations in which rice and noodles are the main carbohydrate source $^{(25-28)}$. Insulin resistance and impaired $\beta$-cell function are key contributors to the development of type 2 diabetes, and chronic inflammation and dyslipidaemia can contribute to these conditions ${ }^{(29,30)}$. To better understand the mechanisms by which rice or noodle intake may be involved in the pathogenesis of type 2 diabetes and its impact on the metabolic traits associated with type 2 diabetes, we evaluated the relationship between rice and noodle consumption and markers of insulin resistance, insulin secretion, inflammation and dyslipidaemia in a cross-sectional study in Singaporean Chinese.

\section{Methods \\ Study population}

The present study used cross-sectional data of the Singapore Prospective Study Program-2 (SP2) cohort. These data were collected from 2004 to 2007. SP2 was a follow-up study of the participants of four population-based studies carried out in Singapore during 1982-8: the Thyroid and Heart Study; the National Health Survey (1992); the National University of Singapore Heart Study; the National Health Survey (1998). These studies selected participants by stratified random sampling of individuals aged 18-69 years with oversampling of ethnic minority groups (i.e. Malays and Asian-Indians) ${ }^{(31)}$. The present study was conducted according to the guidelines laid down in the Declaration of Helsinki, and all procedures involving human subjects were approved by the National University of Singapore and the Singapore General Hospital Institutional Review Boards. Written informed consent was obtained from all the participants.

For SP2, 10747 study subjects qualified for participation, and 7744 completed interviewer-administered questionnaires on demographics, lifestyle and medical history. Of these participants, 5163 made a clinic visit during which blood was drawn and anthropometric parameters and blood pressure were measured. Details on participant recruitment and study methodology have been reported elsewhere ${ }^{(32)}$. As the type of refined grain foods consumed by Indians and Malays can be substantially different and may be less comprehensively represented in our questionnaire, we focused only on the
Chinese subpopulation in the present study. Of the 5163 participants who visited the clinic, 3439 were Chinese. From this subpopulation, we excluded subjects with pre-existing CVD ( $n$ 109), diabetes diagnosis or known diabetes ( $n$ 232), current cancer ( $n 47)$ or a current pregnancy $(n 2)$, as these conditions may affect diet or reporting of dietary intake potentially leading to reverse causation. From the remaining 3088 participants, we also excluded individuals who changed their diet in the month preceding the interview ( $n$ 203) and those with extremes of energy intake ( $>29288$ or $<2092 \mathrm{~kJ}$ $(>7000$ or $<500 \mathrm{kcal})$ ) and extreme energy intake based on the ratio of energy intake:energy expenditure (lowest or highest 2.5 percentage of the ratio, $n 138)^{(33)}$. From the remaining cohort comprising 2758 participants, we further excluded individuals with missing covariates ( $n$ 30). As a result, 2728 persons remained for the analysis.

\section{Assessment of dietary intakes}

A semi-quantitative 169-item FFQ developed by the Institute of Health, Singapore, was used to assess the dietary intake of participants during the month preceding the interview. Food items were selected if they were significant contributors to the intake of energy and selected nutrients in adult Singaporeans based on the National Nutrition Survey. The questionnaire has been validated previously ${ }^{(34)}$. The participants were asked to estimate the frequency of consumption of each food group based on a reference portion size and to indicate consumption on a per-d, per-week or permonth basis or as never/rarely. Daily energy and nutrient intakes were subsequently calculated by the Health Promotion Board based on an in-house database of energy and nutrient values of local foods.

Data on rice intake were obtained by asking the participants about the frequency of consumption of a standard bowl or portion of rice. Household measures such as bowls of different sizes or visual aids for various food groups and individual food items were used to help the participants estimate amounts consumed as fractions or multiples of the illustrated reference portions. In total, ten rice dishes and thirteen noodle dishes were included in the questionnaire. Options for the type of rice consumed included plain rice or plain rice porridge, flavoured rice (e.g. fried rice and chicken rice) and flavoured rice porridge. For noodle intake (mainly rice noodles, wheat noodles, bean noodles or pasta), the questionnaire assessed the consumption of different types of noodles in soup, dry noodles, fried noodles, noodles in lemak gravy (with coconut milk) and other noodles (including instant noodles). One portion of cooked white rice weighs approximately $200 \mathrm{~g}$ and one portion of cooked noodles weighs approximately $275 \mathrm{~g}$.

\section{Assessment of outcome variables}

Fasting venous blood samples were sent to the National University Hospital Reference Laboratory for analysis on the day the blood was drawn for biochemical testing of fasting plasma glucose (FPG; ADVIA 2400, Siemens), glycated 
Hb (Biorad Variant II analyser, Bio-Rad Laboratories), HDL-cholesterol (HDL-C) and TAG. Fasting serum samples were analysed for total cholesterol, TAG and HDL-C (Siemens Medical Solutions Diagnostics), high-sensitivity C-reactive protein (CRP, Roche Diagnostics), total adiponectin (Sekisui Medical Company Limited) and insulin (microparticle enzyme immunoassay, Abbott AXSYM, Abbott Laboratories). LDL-cholesterol concentrations were calculated using the Friedewald equation. The respective intra-batch and interbatch $\mathrm{CV}$ for the variables were as follows: $0.93-1.15$ and $0.56-0.65 \%$ for TAG; $0-3.85$ and $1.18-2.00 \%$ for HDL-C; $1 \cdot 27-3.40$ and $2 \cdot 50-6 \cdot 60 \%$ for glucose; $4.00-4.50 \%$ for insulin; $0-2.00$ and $0.85-1.54 \%$ for glycated $\mathrm{Hb}, 0.60-1.30$ and $2 \cdot 30-3 \cdot 10 \%$ for CRP; $18 \cdot 10$ and $15 \cdot 90 \%$ for adiponectin. Homeostasis model assessment (HOMA) indices were used as measures of insulin resistance and $\beta$-cell function. The HOMA insulin resistance (HOMA-IR) index was computed as FPG $(\mathrm{mmol} / \mathrm{l}) \times$ fasting serum insulin $(\mathrm{mU} / \mathrm{l}) / 22 \cdot 5$, where for insulin $1 \mathrm{mU}=6.00 \mathrm{pmol}$. The HOMA- $\beta$-cell (HOMA- $\beta$ ) index was computed as $20 \times$ fasting serum insulin $(\mathrm{mU} / \mathrm{l}) /$ FPG $(\mathrm{mmol} / \mathrm{l})-3 \cdot 5^{(35)}$.

\section{Assessment of covariates}

Height was measured using a wall-mounted measuring tape and weight using a digital scale. BMI was computed as weight ( $\mathrm{kg}$ ) divided by height $\left(\mathrm{m}^{2}\right)$. Data on alcohol and coffee intake were obtained using the FFQ and those on cigarette smoking status, education level and physical activity the main questionnaire. Total physical activity, expressed as metabolic equivalents of task-h/week, was assessed using a validated questionnaire based on activities in four domains (household, occupational, leisure-time and transport) ${ }^{(33)}$. Data on history of hypertension or dyslipidaemia were obtained from self-reports of physician diagnosis or use of medications to treat these conditions.

\section{Statistical analyses}

The participants were classified into quintiles of rice and noodle consumption, and we compared the characteristics of the participants across the quintiles using ANOVA (for continuous variables with a normal distribution), Kruskal-Wallis tests (for continuous variables with a non-normal distribution) or $\chi^{2}$ tests (for categorical variables). Rice and noodle consumption is expressed as portions per $8368 \mathrm{~kJ}$ (2000 kcal). All the response variables were transformed using natural logarithms to achieve normality. Geometric means and 95\% CI were obtained by exponentiation of means and $95 \% \mathrm{CI}$ of values on the logarithmic scale. Sensitivity analyses were carried out, in which we truncated response variables that were more than $4 \mathrm{SD}$ from the mean to reduce the potential impact of outliers. As this did not materially affect the results, we report results for data without truncation.

We used multiple linear regression analyses to study rice and noodle consumption in relation to biological risk factors. Sociodemographic factors and type 2 diabetes risk factors that were identified from the literature were adjusted for in the analyses as potential confounders. Variables were incorporated into four multivariable models as follows: (1) adjusted for age (years), sex and total energy intake $(\mathrm{kJ} / \mathrm{d})$; (2) further adjusted for physical activity (metabolic equivalents of task-h/ week), alcohol intake (non-drinker, $<1$ serving/d, $\geq 1$ serving/d), cigarette smoking status (non-smoker, ex-smoker, current smoker $<10$ cigarettes/d, current smoker $\geq 10$ cigarettes/d), education level (primary/below, secondary, polytechnic/diploma, university), dyslipidaemia diagnosis or known dyslipidaemia (yes/no) and hypertension diagnosis or known hypertension (yes/no); (3) further adjusted for BMI $\left(\mathrm{kg} / \mathrm{m}^{2}\right)$ and waist:hip ratio; (4) further adjusted for dietary confounders, specifically consumption of coffee (never/ rarely, $<1$ cup daily, $1-2$ cups daily, $\geq 3$ cups daily), protein (\% energy), wholemeal bread ( $0,0 \cdot 1$ to $<1, \geq 1$ serving daily), white bread ( $0,0 \cdot 1$ to $<1, \geq 1$ serving daily), fruits (servings per $8368 \mathrm{~kJ}(2000 \mathrm{kcal})$ ), vegetables (servings per $8368 \mathrm{~kJ}$ (2000 kcal)), cholesterol (mg/8368 kJ (2000 kcal)), ratio of PUFA:SFA and rice (portions per $8368 \mathrm{~kJ}(2000 \mathrm{kcal}))$ or noodles (portions per $8368 \mathrm{~kJ}$ (2000 kcal)) when appropriate. Rice and noodle intakes were fitted as quintiles; bread and coffee intakes were fitted in the categorical scale, while the other dietary variables were modelled in the continuous scale. Analyses with HOMA- $\beta$ as the outcome variable were further adjusted for HOMA-IR. Participants with diagnosed dyslipidaemia were excluded from the analyses with HDL-C or TAG as the outcome variable (remaining sample size $n$ 1978). We also carried out analyses modelling rice and noodle intakes as continuous variables. The regression coefficients are expressed as percentage changes in the outcome variables for each portion increment in rice or noodle intake ${ }^{(36)}$.

Secondary analyses were carried out to evaluate whether associations were similar for men and women and for overweight (BMI $\geq 23 \mathrm{~kg} / \mathrm{m}^{2}$ ) and non-overweight (BMI $<23 \mathrm{~kg} / \mathrm{m}^{2}$ ) individuals using a commonly accepted cut-off value for overweight in Asians ${ }^{(37)}$. A multiplicative interaction term with sex or overweight as a dichotomous variable and rice or noodle intake as a continuous variable was included in the multivariable models. We observed no significant interaction by sex and therefore present the results for men and women together. All the data were analysed using the Statistical Analysis System version 9.2 software (SAS Institute, Inc.). Twosided $P$ values $<0.05$ were considered statistically significant.

\section{Results}

The median intake of rice was 1.57 portions/d ( 1.75 portions/ $8368 \mathrm{~kJ}(2000 \mathrm{kcal}))$ and the median intake of noodles was 0.57 portions/d ( 0.63 daily portions $/ 8368 \mathrm{~kJ}$ (2000 kcal)). Rice and noodle consumption explained $64.6 \%$ of starch intake in the study population independent of total energy intake. The characteristics of the study population according to rice and noodle consumption are given in Table 1 . The study participants were aged between 24.6 and 91.8 years (mean 48.7 (SD 11.5) years). Participants with higher rice intake tended to be older and male, have a low education level, smoke, be less physically active and have hypertension diagnosis or 
Table 1. Characteristics of the study participants according to quintiles of rice and noodle consumption

(Mean values and standard deviations; median values, interquartile ranges and percentages)

\begin{tabular}{|c|c|c|c|c|c|c|c|c|c|c|c|c|}
\hline \multirow[b]{4}{*}{ Characteristics } & \multicolumn{6}{|c|}{ Rice } & \multicolumn{6}{|c|}{ Noodles } \\
\hline & \multirow{2}{*}{\multicolumn{2}{|c|}{$\frac{\text { Quintile } 1 \text { (low) }}{n 546}$}} & \multirow{2}{*}{\multicolumn{2}{|c|}{$\frac{\text { Quintile } 3 \text { (medium) }}{n 545}$}} & \multirow{2}{*}{\multicolumn{2}{|c|}{$\frac{\text { Quintile } 5 \text { (high) }}{n 545}$}} & \multirow{2}{*}{\multicolumn{2}{|c|}{$\frac{\text { Quintile } 1 \text { (low) }}{n 546}$}} & \multirow{2}{*}{\multicolumn{2}{|c|}{$\frac{\text { Quintile } 3 \text { (medium) }}{n 545}$}} & \multirow{2}{*}{\multicolumn{2}{|c|}{$\frac{\text { Quintile } 5 \text { (high) }}{n 545}$}} \\
\hline & & & & & & & & & & & & \\
\hline & Mean & SD & Mean & SD & Mean & SD & Mean & SD & Mean & SD & Mean & SD \\
\hline \multicolumn{13}{|l|}{ Daily intake } \\
\hline Median & \multirow{2}{*}{\multicolumn{2}{|c|}{$\begin{array}{c}0.98 \\
0.77-1.10\end{array}$}} & \multirow{2}{*}{\multicolumn{2}{|c|}{$\begin{array}{c}1.75 \\
1.67-1.84\end{array}$}} & \multirow{2}{*}{\multicolumn{2}{|c|}{$\begin{array}{c}2.79 \\
2.56-3.27\end{array}$}} & \multirow{2}{*}{\multicolumn{2}{|c|}{$\begin{array}{c}0.22 \\
0.12-0.29\end{array}$}} & \multirow{2}{*}{\multicolumn{2}{|c|}{$\begin{array}{c}0.63 \\
0.58-0.68\end{array}$}} & \multirow{2}{*}{\multicolumn{2}{|c|}{$\begin{array}{c}1.21 \\
1.08-1.42\end{array}$}} \\
\hline Interquartile range & & & & & & & & & & & & \\
\hline Age (years) & 45.67 & 10.44 & 47.91 & 10.89 & 52.81 & 11.89 & 52.89 & 11.91 & 47.58 & $11 \cdot 28$ & $47 \cdot 12$ & 10.75 \\
\hline BMI $\left(\mathrm{kg} / \mathrm{m}^{2}\right)$ & 22.65 & 3.58 & 23.07 & 3.86 & 22.54 & 3.55 & 22.56 & 3.46 & 22.47 & 3.58 & 22.98 & 3.56 \\
\hline \multirow{2}{*}{\multicolumn{13}{|c|}{ WHR }} \\
\hline & & & & \multicolumn{9}{|c|}{ Men } \\
\hline Median & \multirow{2}{*}{\multicolumn{2}{|c|}{$\begin{array}{c}0.89 \\
0.85-0.92\end{array}$}} & & & & & & & & & & \\
\hline Interquartile range & & & 0.8 & & 0.8 & & 0.8 & & 0.8 & & 0.8 & \\
\hline Women & & & & & & & & & & & & \\
\hline Median & & & & & & & & & & & & \\
\hline Interquartile range & & & 0.7 & & & & 0.7 & & 0.7 & & 0.7 & \\
\hline $\operatorname{Sex}(\%)$ & & & & & & & & & & & & \\
\hline Men & & & & & & & & & & & & \\
\hline Education (\%) & & & & & & & & & & & & \\
\hline Primary or below & & & & & & & & & & & & \\
\hline Secondary & & & & & & & & & & & & \\
\hline Polytechnic or diploma & & & & & & & & & & & & \\
\hline University & & & & & & & & & & & & \\
\hline Alcohol intake (\%) & & & & & & & & & & & & \\
\hline Coffee consumption (\%) & & & & & & & & & & & & \\
\hline Never/rarely & & & & & & & & & & & & \\
\hline$<1 \mathrm{cup} / \mathrm{d}$ & & & & & & & & & & & & \\
\hline $1-2$ cups/d & & & & & & & & & & & & \\
\hline$\geq 3 \mathrm{cups} / \mathrm{d}$ & & & & & & & & & & & & \\
\hline Cigarette smoking status (\%) & & & & & & & & & & & & \\
\hline Non-smoker & & & & & & & & & & & & \\
\hline Ex-smoker & & & & & & & & & & & & \\
\hline Current, $<10$ cigarettes $/ \mathrm{d}$ & & & & & & & & & & & & \\
\hline Current, $\geq 10$ cigarettes $/ \mathrm{d}$ & & & & & & & & & & & & \\
\hline Physical activity (MET-h/week & & & & & & & & & & & & \\
\hline Median & & & & & & & & & & & & \\
\hline Interquartile range & $10 \cdot 0$ & 3.50 & 7.00 & & 7.0 & & $8 \cdot 6$ & & $7 \cdot 00$ & & 7.0 & \\
\hline Diagnosed dyslipidaemia (\%) & & & & & & & & & & & & \\
\hline Diagnosed hypertension (\%) & & & & & & & & & & & & \\
\hline Energy intake $(\mathrm{kccl} / \mathrm{d})$ & & & & & & & & & & & & \\
\hline Median & & & & & & & & & & & & \\
\hline Interquartile range & 162 & & 141 & & 131 & & 135 & & 150 & & 152 & \\
\hline Energy intake $(\mathrm{kJ} / \mathrm{d})$ & & & & & & & & & & & & \\
\hline Median & & & & & & & & & & & & \\
\hline Interquartile range & 678 & 150 & 5937 & 343 & 549 & & 567 & & 628 & & 637 & 175 \\
\hline Carbohydrate (\% energy) & $52 \cdot 22$ & 6.13 & 55.95 & $5 \cdot 14$ & 61.25 & 5.77 & 57.62 & 7.36 & $56 \cdot 30$ & $6 \cdot 10$ & 55.88 & $5 \cdot 37$ \\
\hline Protein (\% energy) & 15.68 & 2.22 & 14.94 & 1.68 & 14.13 & 1.77 & 14.69 & $2 \cdot 13$ & 14.77 & 1.79 & $15 \cdot 21$ & 1.77 \\
\hline
\end{tabular}




\begin{tabular}{|c|c|c|c|c|c|c|c|c|c|c|c|c|}
\hline \multirow[b]{4}{*}{ Characteristics } & \multicolumn{6}{|c|}{ Rice } & \multicolumn{6}{|c|}{ Noodles } \\
\hline & \multirow{2}{*}{\multicolumn{2}{|c|}{$\frac{\text { Quintile } 1 \text { (low) }}{n 546}$}} & \multirow{2}{*}{\multicolumn{2}{|c|}{$\frac{\text { Quintile } 3 \text { (medium) }}{n 545}$}} & \multirow{2}{*}{\multicolumn{2}{|c|}{$\frac{\text { Quintile } 5 \text { (high) }}{n 545}$}} & \multirow{2}{*}{\multicolumn{2}{|c|}{$\frac{\text { Quintile } 1 \text { (low) }}{n 546}$}} & \multirow{2}{*}{\multicolumn{2}{|c|}{$\frac{\text { Quintile } 3 \text { (medium) }}{n 545}$}} & \multirow{2}{*}{\multicolumn{2}{|c|}{$\frac{\text { Quintile } 5 \text { (high) }}{n 545}$}} \\
\hline & & & & & & & & & & & & \\
\hline & Mean & SD & Mean & SD & Mean & SD & Mean & SD & Mean & SD & Mean & SD \\
\hline Fat (\% energy) & $31 \cdot 81$ & 5.51 & $28 \cdot 82$ & 4.51 & $24 \cdot 33$ & 4.76 & $27 \cdot 42$ & $6 \cdot 11$ & 28.57 & $5 \cdot 23$ & 28.53 & 4.84 \\
\hline Starch (\% energy) & 29.65 & 6.84 & $35 \cdot 81$ & $5 \cdot 12$ & 44.02 & $6 \cdot 72$ & 34.93 & $9 \cdot 69$ & 35.63 & 6.63 & 38.57 & 6.07 \\
\hline Mono- and disaccharides (\% energy) & $22 \cdot 31$ & $7 \cdot 24$ & 19.90 & 5.79 & $17 \cdot 02$ & $5 \cdot 39$ & $22 \cdot 41$ & $7 \cdot 33$ & $20 \cdot 42$ & $5 \cdot 73$ & $17 \cdot 13$ & $5 \cdot 24$ \\
\hline \multicolumn{13}{|l|}{ PUFA:SFA ratio } \\
\hline Median & \multirow{2}{*}{\multicolumn{2}{|c|}{$\begin{array}{c}0.48 \\
0.37-0.74\end{array}$}} & \multirow{2}{*}{\multicolumn{2}{|c|}{$\begin{array}{c}0.51 \\
0.37-0.73\end{array}$}} & \multirow{2}{*}{\multicolumn{2}{|c|}{$\begin{array}{c}0.50 \\
0.38-0.78\end{array}$}} & \multirow{2}{*}{\multicolumn{2}{|c|}{$\begin{array}{c}0.57 \\
0.39-0.87\end{array}$}} & \multirow{2}{*}{\multicolumn{2}{|c|}{$\begin{array}{c}0.51 \\
0.37-0.73\end{array}$}} & \multirow{2}{*}{\multicolumn{2}{|c|}{$\begin{array}{c}0.44 \\
0.36-0.62\end{array}$}} \\
\hline Interquartile range & & & & & & & & & & & & \\
\hline Fibre (g/8368 kJ (2000 kcal)) & $21 \cdot 41$ & $5 \cdot 72$ & $20 \cdot 83$ & 4.39 & $21 \cdot 21$ & 4.66 & $22 \cdot 11$ & $5 \cdot 50$ & $20 \cdot 86$ & 4.48 & $20 \cdot 14$ & $4 \cdot 16$ \\
\hline Cholesterol (mg/4184 kJ (1000 kcal)) & $125 \cdot 97$ & $42 \cdot 66$ & 124.03 & 39.90 & $109 \cdot 17$ & 43.06 & $106 \cdot 46$ & 40.61 & 123.64 & $36 \cdot 14$ & $126 \cdot 79$ & $42 \cdot 00$ \\
\hline Rice $^{*}$ & 0.90 & 0.27 & 1.75 & $0 \cdot 10$ & 3.00 & 0.62 & $2 \cdot 16$ & 0.98 & 1.82 & 0.66 & 1.54 & 0.62 \\
\hline Noodles* & 0.83 & 0.54 & 0.69 & 0.38 & 0.52 & 0.33 & $0 \cdot 20$ & $0 \cdot 11$ & 0.63 & 0.06 & 1.32 & 0.37 \\
\hline Wholemeal bread (portions/d) & 0.44 & 0.82 & 0.32 & 0.77 & 0.23 & 0.62 & 0.51 & 1.01 & 0.31 & 0.65 & $0 \cdot 17$ & 0.44 \\
\hline \multicolumn{13}{|l|}{ White bread (portions/d) } \\
\hline Median & \multirow{2}{*}{\multicolumn{2}{|c|}{$\begin{array}{c}0.57 \\
0.10-1.18\end{array}$}} & \multirow{2}{*}{\multicolumn{2}{|c|}{$\begin{array}{c}0.70 \\
0.61-1.29\end{array}$}} & \multirow{2}{*}{\multicolumn{2}{|c|}{$\begin{array}{c}0.43 \\
0.07-1.00\end{array}$}} & \multirow{2}{*}{\multicolumn{2}{|c|}{$\begin{array}{c}0.64 \\
0.07-1.78\end{array}$}} & \multirow{2}{*}{\multicolumn{2}{|c|}{$\begin{array}{c}0.60 \\
0.14-1.27\end{array}$}} & \multirow{2}{*}{\multicolumn{2}{|c|}{$\begin{array}{c}0.43 \\
0.07-1.00\end{array}$}} \\
\hline Interquartile range & & & & & & & & & & & & \\
\hline \multicolumn{13}{|l|}{ Fruits $^{\star}$} \\
\hline Median & \multirow{2}{*}{\multicolumn{2}{|c|}{$\begin{array}{c}1.00 \\
1.00-2 \cdot 00\end{array}$}} & \multirow{2}{*}{\multicolumn{2}{|c|}{$\begin{array}{c}1.00 \\
1.00-2 \cdot 00\end{array}$}} & \multirow{2}{*}{\multicolumn{2}{|c|}{$\begin{array}{c}1.00 \\
1.00-2 \cdot 00\end{array}$}} & \multirow{2}{*}{\multicolumn{2}{|c|}{$\begin{array}{c}1.00 \\
1.00-2 \cdot 00\end{array}$}} & \multirow{2}{*}{\multicolumn{2}{|c|}{$\begin{array}{c}1.00 \\
1.00-2 \cdot 00\end{array}$}} & \multirow{2}{*}{\multicolumn{2}{|c|}{$\begin{array}{c}1.00 \\
1.00-2.00\end{array}$}} \\
\hline Interquartile range & & & & & & & & & & & & \\
\hline \multicolumn{13}{|l|}{ Vegetables* } \\
\hline Median & & & & & & & & & & & & \\
\hline Interquartile range & $1 \cdot 2$ & & 1.0 & & 0.9 & & 1.0 & & 1.07 & & 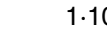 & \\
\hline
\end{tabular}

WHR, waist:hip ratio; MET-h/week, metabolic equivalents of task-h/week.

${ }^{*}$ Expressed in portions per $8368 \mathrm{~kJ}$ (2000 kcal). 
known hypertension. Higher rice consumption was associated with higher intakes of carbohydrate and starch, but with lower intakes of protein, fat, mono- and disaccharides and noodles. Participants with higher noodle intake tended to be younger and be less physically active. Higher noodle consumption was associated with higher intakes of protein and starch, but with lower intakes of carbohydrates, mono- and disaccharides, and fibre and a lower ratio of PUFA:SFA.

Table 2 summarises the concentrations of metabolic markers according to quintiles of rice consumption. Higher rice consumption was not significantly associated with fasting glucose concentrations and HOMA-IR in the basic model adjusted for age, sex and energy intake. However, after further adjustment for potential confounders, particularly BMI and protein and noodle intake, higher rice consumption was strongly associated with higher fasting glucose concentrations and HOMA-IR. Rice consumption was not significantly associated with glycated $\mathrm{Hb}$, CRP, adiponectin, HDL-C, and fasting TAG concentrations and HOMA- $\beta$.

Higher noodle consumption was associated with higher fasting glucose, glycated $\mathrm{Hb}, \mathrm{CRP}$, and fasting TAG concentrations and HOMA-IR, but with lower adiponectin and HDL-C concentrations in the basic model (Table 3). After further adjustment for additional potential confounders, noodle consumption remained significantly directly associated with fasting glucose and TAG concentrations and HOMA-IR. Associations between noodle consumption and other biomarkers were not statistically significant in the fully adjusted model.

In secondary analyses, we examined the odds of having hyperglycaemia using the American Diabetes Association FPG cut-off $\geq 5.6 \mathrm{mmol} / \mathrm{l}^{(38)}$ across the tertiles of rice and noodle consumption (Supplementary Table 1, available online). In the fully adjusted model, we observed higher odds of having high FPG concentrations with higher noodle consumption (OR per portion increment: 1.55; 95\% CI 1.09, $2 \cdot 20 ; P$ trend $=0.01)$, but not with higher rice consumption (0.99; $95 \%$ CI $0.79,1.22 ; P$ trend=0.89).

We also examined the association between total refined grain consumption (the sum of rice and noodle intakes) and metabolic risk factors that were significantly associated with either rice or noodle consumption. Each portion increment in total refined grain consumption was associated with higher FPG concentrations (percentage change 0.92; 95\% CI $0 \cdot 22,1.62 ; P$ trend $=0 \cdot 01$ ), higher fasting TAG concentrations (3.42; $95 \%$ CI $0.33,6.60 ; P$ trend $=0.03)$ and a higher insulin resistance index (4.96; $95 \%$ CI $1.75,8.27 ; P$ trend=0.002).

It has been suggested that the association between refined grain consumption and markers of hyperglycaemia may be more pronounced among overweight individuals ${ }^{(39,40)}$. Therefore, we evaluated the possible interaction of rice and noodle consumption with overweight status (BMI $\geq 23 \mathrm{~kg} / \mathrm{m}^{2}$ ) in relation to metabolic risk factors for which we observed significant associations in the main analysis (Supplementary Tables 2 and 3, available online). The direct association between noodle consumption and HOMA-IR was stronger in the overweight group (change per portion $13.15 \%$, 95\% CI $3.02,24.29)$ than in the leaner group $(1.49 \%, 95 \% \mathrm{CI}-5.02$,
8.45; $P$ interaction $=0 \cdot 001$ ). However, the direct association between rice consumption and HOMA-IR tended to be weaker in the overweight participants (1.88\%, 95\% CI $-3.69,7.78)$ than in the leaner participants $(6.87 \%, 95 \% \mathrm{CI}$ $2 \cdot 80,11 \cdot 10, P$ interaction $=0 \cdot 33)$.

\section{Discussion}

In the present population-based study of 2728 Singaporean Chinese adult men and women, high consumption of rice and noodles was found to be associated with higher fasting glucose concentrations and a higher HOMA index for insulin resistance. In contrast, rice and noodle consumption was found to be not associated with adiponectin or CRP concentrations after adjustment for potential confounders. The present results thus suggest that high consumption of refined grains may contribute to hyperglycaemia through greater insulin resistance, rather than through increased systemic inflammation.

The results obtained for rice consumption in the present study are consistent with the findings of several other studies carried out in Asian populations in which white rice intake is high. Higher consumption of rice was found to be significantly associated with a higher risk of type 2 diabetes in a cohort of older Shanghai women (relative risk 1.78; $95 \%$ CI 1.48, $2 \cdot 15$ for $\geq 300 v .<200 \mathrm{~g} / \mathrm{d})^{(10)}$. In a Japanese cohort, higher rice consumption was also reported to be associated with a higher risk of type 2 diabetes in women (relative risk 1.65; $95 \%$ CI $1 \cdot 06,2.57$ for $\geq 420 v .<200 \mathrm{~g} / \mathrm{d}$ ), but not in men ${ }^{(11)}$ In a cross-sectional study carried out in India, high refined grain consumption (of which white rice comprised $75.8 \%$ ) was found to be associated with a higher prevalence of newly diagnosed type 2 diabetes ${ }^{(27)}$. In the same study, higher refined grain consumption was found to be associated with significantly $7 \cdot 9 \%$ higher fasting glucose concentrations, 13.6\% higher HOMA-IR values, 36.5\% higher serum TAG concentrations and $10.1 \%$ lower HDL-C concentrations for the highest (median $449 \mathrm{~g} / \mathrm{d}$ ) $v$. the lowest (median $218 \mathrm{~g} / \mathrm{d}$ ) quartile $^{(18)}$. In a cross-sectional study in Japanese female farmers, white rice was found to be the major contributor to the dietary glycaemic load, which is associated with higher fasting TAG and glucose concentrations and lower HDL-C concentrations $^{(41)}$.

Few studies on noodle consumption in relation to metabolic risk factors or risk of type 2 diabetes have been carried out. In a study in Hong Kong Chinese, higher consumption of rice, noodles and pasta was found to be associated with a significantly higher prevalence of newly diagnosed type 2 diabetes. However, specific results for noodles were not reported ${ }^{(25)}$. In a Japanese cohort, consumption of noodles was found to be not associated with the risk of type 2 diabetes ${ }^{(11)}$. It is possible that differences in the type of noodles consumed (e.g. wholegrain buckwheat noodles are commonly consumed in Japan but not in Singapore) are responsible for these differences in association. In the present study, we observed stronger associations between noodle consumption and metabolic risk markers than between rice consumption and the markers. In Singapore, both rice and wheat-based noodles typically 
Table 2. Metabolic risk factors according to quintiles of rice consumption

(Geometric means and $95 \%$ confidence intervals; median values and interquartile ranges)

\begin{tabular}{|c|c|c|c|c|c|c|c|c|c|c|c|c|c|}
\hline \multirow[b]{2}{*}{ Characteristics } & \multicolumn{2}{|c|}{ Quintile 1 ( $n 546)$} & \multicolumn{2}{|c|}{ Quintile 2 ( $n 546)$} & \multicolumn{2}{|c|}{ Quintile 3 ( $n 545)$} & \multicolumn{2}{|c|}{ Quintile 4 ( $n 546$ ) } & \multicolumn{2}{|c|}{ Quintile 5 ( $n$ 545) } & \multicolumn{2}{|c|}{$\begin{array}{l}\text { Percentage change } \\
\text { per portion* }\end{array}$} & \multirow[b]{2}{*}{$\begin{array}{c}P \text { for } \\
\text { trend }\end{array}$} \\
\hline & $\begin{array}{c}\text { Geometric } \\
\text { mean }\end{array}$ & $95 \% \mathrm{Cl}$ & $\begin{array}{c}\text { Geometric } \\
\text { mean }\end{array}$ & $95 \% \mathrm{Cl}$ & $\begin{array}{c}\text { Geometric } \\
\text { mean }\end{array}$ & $95 \% \mathrm{Cl}$ & $\begin{array}{c}\text { Geometric } \\
\text { mean }\end{array}$ & $95 \% \mathrm{Cl}$ & $\begin{array}{c}\text { Geometric } \\
\text { mean }\end{array}$ & $95 \% \mathrm{Cl}$ & $\begin{array}{c}\text { Geometric } \\
\text { mean }\end{array}$ & $95 \% \mathrm{Cl}$ & \\
\hline \multicolumn{14}{|c|}{ Daily portion intake } \\
\hline Median & \multirow{2}{*}{\multicolumn{2}{|c|}{$\begin{array}{c}0.98 \\
0.77-1 \cdot 10\end{array}$}} & \multirow{2}{*}{\multicolumn{2}{|c|}{$\begin{array}{c}1.40 \\
1.32-1.50\end{array}$}} & \multirow{2}{*}{\multicolumn{2}{|c|}{$\begin{array}{c}1.75 \\
1.67-1.84\end{array}$}} & \multirow{2}{*}{\multicolumn{2}{|c|}{$\begin{array}{c}2 \cdot 15 \\
2.04-2 \cdot 27\end{array}$}} & \multirow{2}{*}{\multicolumn{2}{|c|}{$\begin{array}{c}2.79 \\
2.56-3.27\end{array}$}} & \multirow{2}{*}{\multicolumn{2}{|c|}{$\begin{array}{l}- \\
-\end{array}$}} & - \\
\hline $\begin{array}{l}\text { Interquartile } \\
\text { range }\end{array}$ & & & & & & & & & & & & & \\
\hline \multicolumn{14}{|l|}{ FPG (mmol/l) } \\
\hline Model 1‡ & 4.71 & $4.66,4.77$ & 4.75 & $4.70,4.80$ & 4.80 & $4.75,4.85$ & 4.83 & $4.78,4.88$ & 4.78 & $4.73,4.83$ & 0.22 & $-0.44,0.89$ & 0.51 \\
\hline Model $2 \S$ & 4.76 & $4.67,4 \cdot 84$ & 4.80 & $4.72,4.88$ & 4.84 & $4.76,4.93$ & 4.88 & $4.79,4.96$ & 4.83 & $4.74,4.91$ & 0.22 & $-0.45,0.90$ & 0.52 \\
\hline Model 3\| & 4.73 & $4.65,4 \cdot 81$ & 4.78 & $4 \cdot 71,4 \cdot 86$ & 4.81 & $4.73,4.89$ & 4.85 & $4.77,4.92$ & 4.82 & $4.74,4.90$ & 0.41 & $-0.23,1.07$ & 0.21 \\
\hline Model 4ף & 4.70 & $4.61,4.78$ & 4.76 & $4.68,4.84$ & 4.80 & $4.71,4.88$ & 4.84 & $4.75,4.92$ & 4.83 & $4.74,4.92$ & 0.81 & $0.09,1.54$ & 0.03 \\
\hline \multicolumn{14}{|l|}{ HbA1c (\%) } \\
\hline Model 1 & 5.68 & $5 \cdot 63,5 \cdot 73$ & 5.69 & $5 \cdot 65,5 \cdot 74$ & 5.75 & $5 \cdot 70,5 \cdot 80$ & 5.72 & $5 \cdot 67,5 \cdot 77$ & $5 \cdot 72$ & $5 \cdot 67,5 \cdot 77$ & 0.18 & $-0.34,0.71$ & 0.49 \\
\hline Model 2 & 5.73 & $5 \cdot 65,5 \cdot 81$ & 5.75 & $5 \cdot 67,5 \cdot 82$ & 5.80 & $5 \cdot 72,5 \cdot 88$ & 5.76 & $5 \cdot 68,5 \cdot 84$ & 5.76 & $5 \cdot 69,5 \cdot 84$ & 0.05 & $-0.47,0.58$ & 0.84 \\
\hline Model 3 & $5 \cdot 71$ & $5.64,5.79$ & 5.73 & $5 \cdot 66,5 \cdot 81$ & 5.77 & $5 \cdot 70,5 \cdot 85$ & 5.74 & $5 \cdot 66,5 \cdot 81$ & 5.76 & $5 \cdot 68,5 \cdot 84$ & 0.19 & $-0.33,0.71$ & 0.48 \\
\hline Model 4 & 5.69 & $5 \cdot 61,5 \cdot 78$ & 5.71 & $5.64,5.79$ & 5.76 & $5.68,5.84$ & 5.73 & $5.65,5.81$ & $5 \cdot 76$ & $5.67,5.84$ & 0.29 & $-0.29,0.86$ & 0.33 \\
\hline \multicolumn{14}{|l|}{ HOMA-IR } \\
\hline Model 1 & $1 \cdot 19$ & $1 \cdot 12,1 \cdot 26$ & $1 \cdot 13$ & $1.07,1.20$ & 1.26 & $1 \cdot 20,1 \cdot 34$ & 1.25 & $1 \cdot 19,1 \cdot 33$ & 1.23 & $1 \cdot 16,1 \cdot 30$ & 1.79 & $-1 \cdot 70,5 \cdot 39$ & 0.32 \\
\hline Model 2 & $1 \cdot 26$ & $1 \cdot 15,1.37$ & 1.22 & $1 \cdot 11,1.33$ & 1.33 & $1.22,1.46$ & 1.34 & $1.23,1.46$ & 1.30 & $1 \cdot 19,1.42$ & 1.79 & $-1.66,5.36$ & 0.31 \\
\hline Model 3 & 1.19 & $1 \cdot 10,1 \cdot 28$ & 1.18 & $1.09,1.27$ & 1.25 & $1 \cdot 16,1.34$ & 1.25 & $1 \cdot 16,1.35$ & 1.29 & $1 \cdot 20,1 \cdot 39$ & 3.78 & $0.81,6.85$ & 0.01 \\
\hline Model 4 & $1 \cdot 16$ & $1.08,1.26$ & $1 \cdot 16$ & $1.08,1.26$ & 1.24 & $1.14,1.34$ & 1.25 & $1 \cdot 16,1 \cdot 36$ & 1.29 & $1 \cdot 19,1 \cdot 40$ & 4.62 & $1.29,8.07$ & 0.01 \\
\hline \multicolumn{14}{|l|}{ HOMA- $\beta$} \\
\hline Model 1 & 101.95 & $97.51,106.59$ & 96.44 & $92 \cdot 36,100 \cdot 70$ & 96.49 & $92.45,100.71$ & 92.31 & $88.43,96 \cdot 36$ & 97.44 & $93 \cdot 24,101 \cdot 84$ & -0.07 & $-2 \cdot 70,2 \cdot 62$ & 0.96 \\
\hline Model 2 & 101.60 & $94.76,108.94$ & 96.05 & $89.72,102.83$ & $96 \cdot 14$ & $89.66,103.09$ & 92.07 & $85.98,98.58$ & 96.58 & $90.04,103.59$ & -0.34 & $-3.00,2.40$ & 0.81 \\
\hline Model 3 & 101.80 & $94.94,109 \cdot 17$ & $96 \cdot 18$ & $89.83,102.97$ & $96 \cdot 37$ & $89.87,103.34$ & $92 \cdot 30$ & $86 \cdot 20,98 \cdot 83$ & 96.38 & $89.86,103.38$ & -0.52 & $-3 \cdot 17,2 \cdot 22$ & 0.71 \\
\hline Model 4 & $105 \cdot 00$ & $97.57,113.00$ & 98.62 & $91.80,105.95$ & $98 \cdot 11$ & $91 \cdot 10,105.66$ & 93.44 & $86.92,100 \cdot 46$ & 95.91 & $88.84,103.55$ & -2.09 & $-4.99,0.90$ & 0.17 \\
\hline \multicolumn{14}{|c|}{ Adiponectin $(\mu \mathrm{g} / \mathrm{ml})$} \\
\hline Model 1 & 3.37 & $3.22,3.52$ & 3.45 & $3.30,3.60$ & 3.22 & $3.08,3.36$ & 3.36 & $3.22,3.51$ & 3.48 & $3.33,3.64$ & 2.07 & $-0.60,4.82$ & 0.13 \\
\hline Model 2 & 3.22 & $3.00,3.45$ & 3.28 & $3.06,3.50$ & 3.06 & $2 \cdot 86,3 \cdot 28$ & $3 \cdot 19$ & $2.98,3.41$ & 3.30 & $3.08,3.53$ & 1.62 & $-1.06,4.38$ & 0.24 \\
\hline Model 3 & $3 \cdot 32$ & $3.12,3.54$ & 3.33 & $3.13,3.55$ & $3 \cdot 17$ & $2.97,3.38$ & 3.30 & $3 \cdot 10,3 \cdot 51$ & 3.32 & $3.12,3.55$ & 0.64 & $-1.83,3.18$ & 0.62 \\
\hline Model 4 & 3.36 & $3.14,3.60$ & 3.36 & $3.15,3.59$ & $3 \cdot 20$ & $2.99,3.43$ & 3.32 & $3.11,3.55$ & 3.34 & $3.12,3.59$ & 0.56 & $-2 \cdot 20,3 \cdot 39$ & 0.7 \\
\hline $\mathrm{CRP}(\mathrm{mg} / \mathrm{l})$ & & & & & & & & & & & & & \\
\hline Model 1 & 0.87 & $0.79,0.96$ & 0.88 & $0.80,0.96$ & 0.96 & $0.87,1.06$ & 0.95 & $0.86,1.04$ & 0.92 & $0.84,1.02$ & 2.65 & $-3.19,8.84$ & 0.38 \\
\hline Model 2 & 0.88 & $0.76,1.02$ & 0.90 & $0.78,1.04$ & 0.95 & $0.82,1 \cdot 11$ & 0.95 & $0.82,1 \cdot 10$ & 0.89 & $0.77,1.04$ & 0.40 & $-5.32,6.45$ & 0.89 \\
\hline Model 3 & 0.83 & $0.72,0.95$ & 0.87 & $0.76,1.00$ & 0.88 & $0.77,1.01$ & 0.88 & $0.77,1.01$ & 0.89 & $0.78,1.03$ & 2.89 & $-2.47,8.54$ & 0.3 \\
\hline Model 4 & 0.83 & $0.72,0.96$ & 0.85 & $0.74,0.98$ & 0.86 & $0.74,0.99$ & 0.86 & $0.75,0.99$ & 0.87 & $0.74,1.01$ & 1.30 & $-4.54,7.50$ & 0.67 \\
\hline HDL-cholesterol & $\mathrm{mol} / /)^{* *}$ & & & & & & & & & & & & \\
\hline Model 1 & 1.45 & $1.42,1.49$ & 1.45 & $1 \cdot 42,1.48$ & 1.42 & $1.39,1.45$ & 1.42 & $1.39,1.46$ & 1.45 & $1.42,1.49$ & -0.17 & $-1.55,1.22$ & 0.81 \\
\hline Model 2 & 1.47 & $1.42,1.52$ & 1.46 & $1.41,1.51$ & 1.44 & $1.39,1.49$ & 1.44 & $1.39,1.49$ & 1.48 & $1.43,1.53$ & 0.22 & $-1.17,1.63$ & 0.76 \\
\hline Model 3 & 1.48 & $1.44,1.53$ & 1.47 & $1.42,1.52$ & 1.46 & $1.41,1.51$ & 1.46 & $1.41,1.51$ & 1.48 & $1.43,1.53$ & -0.24 & $-1.55,1.08$ & 0.72 \\
\hline Model 4 & 1.49 & $1.44,1.54$ & 1.47 & $1.42,1.52$ & 1.46 & $1.41,1.52$ & 1.46 & $1.41,1.52$ & 1.48 & $1.43,1.54$ & -0.44 & $-1.89,1.03$ & 0.55 \\
\hline Fasting TAG (m & $(1)^{\star \star}$ & & & & & & & & & & & & \\
\hline Model 1 & 1.00 & $0.95,1.05$ & 1.01 & $0.96,1.06$ & $1 \cdot 11$ & $1 \cdot 05,1 \cdot 16$ & 1.06 & $1.01,1.12$ & 1.04 & $0.99,1.09$ & 1.94 & $-1 \cdot 10,5.08$ & 0.21 \\
\hline Model 2 & $1 \cdot 16$ & $1.07,1.25$ & $1 \cdot 16$ & $1.08,1.25$ & 1.28 & $1 \cdot 18,1.38$ & 1.21 & $1.13,1.31$ & $1 \cdot 18$ & $1.09,1.27$ & 0.89 & $-2.13,4.01$ & 0.57 \\
\hline Model 3 & 1.12 & $1.05,1.21$ & 1.15 & $1.07,1.23$ & 1.24 & $1.15,1.34$ & $1 \cdot 18$ & $1 \cdot 10,1.26$ & 1.18 & $1.09,1.26$ & 1.97 & $-0.89,4.91$ & 0.18 \\
\hline Model 4 & 1.11 & $1.03,1 \cdot 19$ & 1.13 & $1.05,1.22$ & 1.22 & $1 \cdot 13,1.32$ & $1 \cdot 16$ & $1.08,1.25$ & $1 \cdot 16$ & $1.07,1.26$ & 2.08 & $-1 \cdot 10,5 \cdot 36$ & 0.2 \\
\hline
\end{tabular}

FPG, fasting plasma glucose; HbA1c, glycated Hb; HOMA-IR, homeostasis model assessment of insulin resistance; HOMA- $\beta$, homeostasis model assessment of $\beta$-cell function; CRP, C-reactive protein. *Percentage changes (and $95 \% \mathrm{Cl}$ ) in plasma concentrations of metabolic risk factors for each portion increment of rice, approximately $200 \mathrm{~g}$ of cooked rice. † From multiple linear regression models for the relationship between rice consumption and log-transformed markers.

\pm Adjusted for age, sex and energy intake. HOMA- 3 models were further adjusted for HOMA-IR.

$\S$ Further adjusted for physical activity, alcohol intake, smoking status, education level, diagnosed dyslipidaemia and diagnosed hypertension

Further adjusted for BMl and waist:hip ratio. 
Table 3. Metabolic risk factors according to quintiles of noodle consumption

(Geometric means and $95 \%$ confidence intervals; median values and interquartile ranges)

\begin{tabular}{|c|c|c|c|c|c|c|c|c|c|c|c|c|c|}
\hline \multirow[b]{2}{*}{ Characteristics } & \multicolumn{2}{|c|}{ Quintile 1 ( $n 546$ ) } & \multicolumn{2}{|c|}{ Quintile 2 ( $n 546)$} & \multicolumn{2}{|c|}{ Quintile 3 (n 545) } & \multicolumn{2}{|c|}{ Quintile 4 (n 546) } & \multicolumn{2}{|c|}{ Quintile 5 ( $n$ 545) } & \multicolumn{2}{|c|}{$\begin{array}{l}\text { Percentage change per } \\
\text { portion }^{*}\end{array}$} & \multirow[b]{2}{*}{$\begin{array}{l}P \text { for } \\
\text { trend }\end{array}$} \\
\hline & $\begin{array}{l}\text { Geometric } \\
\text { mean }\end{array}$ & $95 \% \mathrm{Cl}$ & $\begin{array}{c}\text { Geometric } \\
\text { mean }\end{array}$ & $95 \% \mathrm{Cl}$ & $\begin{array}{l}\text { Geometric } \\
\text { mean }\end{array}$ & $95 \% \mathrm{Cl}$ & $\begin{array}{l}\text { Geometric } \\
\text { mean }\end{array}$ & $95 \% \mathrm{Cl}$ & $\begin{array}{l}\text { Geometric } \\
\text { mean }\end{array}$ & $95 \% \mathrm{Cl}$ & $\begin{array}{l}\text { Geometric } \\
\text { mean }\end{array}$ & $95 \% \mathrm{Cl}$ & \\
\hline \multicolumn{14}{|c|}{ Daily portion intake } \\
\hline Median & \multirow{2}{*}{\multicolumn{2}{|c|}{$\begin{array}{c}0.22 \\
0.12-0.29\end{array}$}} & \multirow{2}{*}{\multicolumn{2}{|c|}{$\begin{array}{c}0.45 \\
0.40-0.49\end{array}$}} & \multirow{2}{*}{\multicolumn{2}{|c|}{$\begin{array}{c}0.63 \\
0.58-0.68\end{array}$}} & \multirow{2}{*}{\multicolumn{2}{|c|}{$\begin{array}{c}0.84 \\
0.78-0.91\end{array}$}} & \multirow{2}{*}{\multicolumn{2}{|c|}{$\begin{array}{c}1.21 \\
1.08-1.42\end{array}$}} & \multirow{2}{*}{\multicolumn{2}{|c|}{$\begin{array}{l}- \\
-\end{array}$}} & - \\
\hline $\begin{array}{l}\text { Interquartile } \\
\text { range }\end{array}$ & & & & & & & & & & & & & \\
\hline \multicolumn{14}{|l|}{$\mathrm{FPG}(\mathrm{mmol} / \mathrm{l})$} \\
\hline Model $1 \neq$ & 4.70 & $4.65,4.75$ & 4.79 & $4.74,4.84$ & 4.75 & $4 \cdot 70,4 \cdot 80$ & 4.79 & $4.74,4.84$ & 4.85 & $4.79,4.90$ & 2.09 & $0.93,3.27$ & $<0.001$ \\
\hline Model $2 \S$ & 4.75 & $4 \cdot 66,4 \cdot 83$ & 4.83 & $4.75,4.92$ & 4.79 & $4 \cdot 71,4 \cdot 87$ & 4.82 & $4.74,4.91$ & 4.88 & $4.80,4.96$ & 1.86 & $0.70,3.05$ & 0.002 \\
\hline Model $3 \|$ & 4.74 & $4.66,4.82$ & 4.81 & $4.73,4.89$ & 4.78 & $4 \cdot 70,4 \cdot 86$ & 4.79 & $4.71,4.87$ & 4.85 & $4.78,4.93$ & 1.50 & $0.38,2.64$ & 0.01 \\
\hline Model 4ף & 4.73 & $4.65,4.81$ & 4.79 & $4.71,4.88$ & 4.77 & $4.68,4.85$ & 4.78 & $4.69,4.86$ & 4.85 & $4.76,4.94$ & 1.67 & $0.44,2.92$ & 0.01 \\
\hline \multicolumn{14}{|l|}{ HbA1c (\%) } \\
\hline Model 1 & 5.69 & $5.64,5.73$ & $5 \cdot 70$ & $5.65,5.74$ & 5.68 & $5.64,5.73$ & 5.73 & $5.68,5.78$ & 5.77 & $5.72,5 \cdot 82$ & 1.43 & $0.52,2.34$ & 0.002 \\
\hline Model 2 & 5.73 & $5 \cdot 65,5 \cdot 81$ & 5.74 & $5 \cdot 66,5 \cdot 82$ & 5.73 & $5 \cdot 65,5 \cdot 81$ & 5.77 & $5 \cdot 70,5 \cdot 85$ & $5 \cdot 80$ & $5 \cdot 72,5 \cdot 88$ & 1.16 & $0.25,2 \cdot 08$ & 0.01 \\
\hline Model 3 & 5.73 & $5 \cdot 65,5 \cdot 80$ & 5.72 & $5 \cdot 64,5 \cdot 79$ & 5.72 & $5 \cdot 65,5 \cdot 80$ & 5.75 & $5 \cdot 67,5.82$ & 5.78 & $5 \cdot 70,5 \cdot 85$ & 0.95 & $0.07,1.85$ & 0.04 \\
\hline Model 4 & 5.73 & $5.65,5.81$ & $5 \cdot 71$ & $5.63,5.79$ & 5.72 & $5.64,5.79$ & 5.74 & $5.66,5.82$ & 5.77 & $5.69,5.85$ & 0.85 & $-0.12,1.84$ & 0.09 \\
\hline \multicolumn{14}{|l|}{ HOMA-IR } \\
\hline Model 1 & $1 \cdot 17$ & $1 \cdot 11,1.24$ & $1 \cdot 17$ & $1 \cdot 10,1 \cdot 23$ & $1 \cdot 16$ & $1 \cdot 10,1 \cdot 23$ & 1.27 & $1 \cdot 20,1 \cdot 34$ & 1.30 & $1 \cdot 23,1 \cdot 37$ & $10 \cdot 64$ & $4 \cdot 19,17 \cdot 50$ & 0.001 \\
\hline Model 2 & 1.25 & $1.14,1.37$ & 1.24 & $1.14,1.35$ & 1.23 & $1.12,1.34$ & 1.33 & $1.22,1.45$ & 1.36 & $1.25,1.48$ & 8.64 & $2 \cdot 40,15 \cdot 27$ & 0.01 \\
\hline Model 3 & 1.23 & $1.14,1.32$ & $1 \cdot 17$ & $1.09,1.27$ & 1.21 & $1 \cdot 12,1 \cdot 30$ & 1.23 & $1.15,1.33$ & 1.28 & $1.19,1.38$ & 4.74 & $-0.38,10 \cdot 12$ & 0.07 \\
\hline Model 4 & 1.22 & $1.13,1.32$ & $1 \cdot 16$ & $1.08,1.26$ & $1 \cdot 20$ & $1 \cdot 11,1 \cdot 30$ & 1.23 & $1 \cdot 13,1 \cdot 33$ & 1.29 & $1.19,1.40$ & $6 \cdot 17$ & $0.49,12.16$ & 0.03 \\
\hline \multicolumn{14}{|l|}{ HOMA- $\beta$} \\
\hline Model 1 & 102.52 & $98 \cdot 16,107.06$ & 92.96 & $89.07,97.02$ & 97.14 & $93.07,101.40$ & 97.88 & $93 \cdot 77,102 \cdot 17$ & 94.01 & $90.05,98 \cdot 13$ & $-4 \cdot 17$ & $-8.49,0.35$ & 0.07 \\
\hline Model 2 & $102 \cdot 24$ & $95.29,109.70$ & $92 \cdot 71$ & $86.51,99 \cdot 36$ & 97.08 & $90.65,103.97$ & 97.67 & $91 \cdot 18,104 \cdot 62$ & 93.93 & $87.81,100.49$ & -3.97 & $-8.34,0.61$ & 0.09 \\
\hline Model 3 & $102 \cdot 19$ & $95.24,109.65$ & 92.94 & $86.73,99.61$ & $97 \cdot 10$ & $90.67,103.99$ & 97.85 & $91.34,104.83$ & 94.02 & $87.89,100.57$ & -3.89 & $-8.26,0.69$ & 0.1 \\
\hline Model 4 & $103 \cdot 21$ & $95.90,111.08$ & $94 \cdot 60$ & $87.96,101 \cdot 74$ & $98 \cdot 74$ & $91.84,106 \cdot 16$ & 99.24 & $92 \cdot 25,106 \cdot 77$ & $95 \cdot 18$ & $88.35,102.53$ & -4.16 & $-8.92,0.85$ & 0.1 \\
\hline \multicolumn{14}{|c|}{ Adiponectin $(\mu \mathrm{g} / \mathrm{ml})$} \\
\hline Model 1 & 3.50 & $3.35,3.65$ & 3.40 & $3.25,3.54$ & 3.38 & $3.24,3.53$ & 3.26 & $3.12,3 \cdot 40$ & 3.35 & $3.20,3.49$ & -5.03 & $-9.29,-0.58$ & 0.03 \\
\hline Model 2 & 3.31 & $3.09,3.54$ & 3.23 & $3.02,3.46$ & 3.23 & $3.01,3.45$ & 3.13 & $2.92,3.35$ & 3.21 & $3.00,3.43$ & $-4 \cdot 18$ & $-8.49,0.32$ & 0.07 \\
\hline Model 3 & 3.35 & $3.14,3.57$ & 3.32 & $3.12,3.54$ & 3.26 & $3.06,3.47$ & 3.25 & $3.05,3.46$ & 3.31 & $3.11,3.52$ & -2.25 & $-6 \cdot 34,2.02$ & 0.3 \\
\hline Model 4 & 3.36 & $3.14,3 \cdot 60$ & 3.34 & $3.12,3.57$ & 3.28 & $3.07,3.51$ & 3.28 & $3.06,3.50$ & 3.34 & $3.11,3.58$ & $-2 \cdot 27$ & $-6.76,2.43$ & 0.34 \\
\hline $\mathrm{CRP}(\mathrm{mg} / \mathrm{l})$ & & & & & & & & & & & & & \\
\hline Model 1 & 0.87 & $0.79,0.96$ & 0.84 & $0.76,0.92$ & 0.93 & $0.85,1.02$ & 0.98 & $0.90,1.08$ & 0.96 & $0.87,1.06$ & $16 \cdot 75$ & $5 \cdot 54,29 \cdot 16$ & 0.003 \\
\hline Model 2 & 0.88 & $0.76,1.02$ & 0.85 & $0.73,0.98$ & 0.93 & $0.80,1.08$ & 0.97 & $0.84,1 \cdot 12$ & 0.93 & $0.81,1.08$ & $12 \cdot 24$ & $1 \cdot 51,24 \cdot 10$ & 0.02 \\
\hline Model 3 & 0.87 & $0.76,1.00$ & 0.80 & $0.70,0.92$ & 0.91 & $0.80,1.05$ & 0.90 & $0.78,1.03$ & 0.87 & $0.76,1.00$ & 6.94 & $-2 \cdot 44,17 \cdot 23$ & 0.15 \\
\hline Model 4 & 0.87 & $0.97,1.01$ & 0.78 & $0.68,0.90$ & 0.89 & $0.77,1.03$ & 0.87 & $0.76,1.01$ & 0.86 & $0.74,1.00$ & 7.59 & $-2 \cdot 71,18 \cdot 97$ & 0.15 \\
\hline HDL-cholesterol & $\mathrm{mmol} / /)^{* *}$ & & & & & & & & & & & & \\
\hline Model 1 & 1.48 & $1.45,1.52$ & 1.43 & $1.40,1.46$ & 1.47 & $1.43,1.50$ & 1.42 & $1.39,1.45$ & 1.40 & $1.37,1.44$ & -3.69 & $-6.00,-1.32$ & 0.002 \\
\hline Model 2 & 1.50 & $1.45,1.56$ & 1.44 & $1.40,1.50$ & 1.48 & $1.43,1.54$ & 1.44 & $1.39,1.49$ & 1.43 & $1.38,1.48$ & -3.31 & $-5.63,-0.94$ & 0.01 \\
\hline Model 3 & 1.50 & $1.45,1.55$ & 1.46 & $1.41,1.51$ & 1.49 & $1.44,1.54$ & 1.46 & $1.42,1.51$ & 1.45 & $1.40,1.49$ & $-2 \cdot 28$ & $-4.50,-0.01$ & 0.05 \\
\hline Model 4 & 1.51 & $1.45,1.56$ & 1.46 & $1.41,1.51$ & 1.49 & $1.44,1.54$ & 1.47 & $1.42,1.52$ & 1.45 & $1.40,1.50$ & -2.24 & $-4.65,0.24$ & 0.08 \\
\hline Fasting TAG (m & $|0| / /)^{\star \star}$ & & & & & & & & & & & & \\
\hline Model 1 & 0.99 & $0.94,1.04$ & 1.03 & $0.98,1.08$ & 0.99 & $0.95,1.04$ & $1 \cdot 10$ & $1 \cdot 05,1 \cdot 15$ & $1 \cdot 11$ & $1 \cdot 06,1 \cdot 17$ & 11.62 & $5.86,17 \cdot 69$ & $<0.001$ \\
\hline Model 2 & $1 \cdot 14$ & $1.05,1.23$ & $1 \cdot 18$ & $1 \cdot 10,1 \cdot 27$ & $1 \cdot 13$ & $1 \cdot 05,1 \cdot 22$ & 1.25 & $1 \cdot 16,1 \cdot 34$ & 1.25 & $1 \cdot 16,1 \cdot 35$ & $9 \cdot 30$ & $3 \cdot 68,15 \cdot 22$ & 0.001 \\
\hline Model 3 & $1 \cdot 13$ & $1.05,1.22$ & 1.15 & $1.07,1.24$ & $1 \cdot 13$ & $1.05,1.21$ & 1.21 & $1.12,1.29$ & 1.21 & $1 \cdot 13,1 \cdot 30$ & 6.67 & $1.52,12.08$ & 0.01 \\
\hline Model 4 & $1 \cdot 11$ & $1.03,1.20$ & 1.14 & $1.05,1.22$ & 1.11 & $1.03,1.20$ & $1 \cdot 20$ & $1.11,1.29$ & $1 \cdot 22$ & $1.13,1.32$ & 9.17 & $3 \cdot 44,15 \cdot 22$ & 0.001 \\
\hline
\end{tabular}

FPG, fasting plasma glucose; HbA1c, glycated Hb; HOMA-IR, homeostasis model assessment of insulin resistance; HOMA- $\beta$, homeostasis model assessment of $\beta$-cell function; CRP, C-reactive protein.

* Percentage changes (and $95 \% \mathrm{Cl}$ ) in plasma concentrations of metabolic risk factors for each portion increment of noodles, approximately $275 \mathrm{~g}$ of cooked noodles.

†From multiple linear regression models for the relationship between noodle consumption and log-transformed markers.

$\ddagger$ Adjusted for age, sex and energy intake. HOMA- $\beta$ models were further adjusted for HOMA-IR.

§ Further adjusted for physical activity, alcohol intake, smoking status, education level, diagnosed dyslipidaemia and diagnosed hypertension.

$\|$ Further adjusted for BMI and waist:hip ratio.

II Further adjusted for coffee consumption and intake of protein, rice, wholemeal bread, white bread, fruits, vegetables, cholesterol and ratio of PUFA:SFA.

${ }^{* *}$ Participants with diagnosed dyslipidaemia were excluded from HDL-cholesterol and TAG analyses (remaining sample size $n$ 1978, whereby $n_{1} 373, n_{2} 407, n_{3} 405, n_{4} 405$ and $n_{5} 388$ for quintiles $1-5$, respectively). 
prepared from refined grains are commonly consumed. Also, noodle-based dishes are often prepared with lard and typically contain high amounts of $\mathrm{Na}$ and cholesterol. It is possible that addition of these ingredients to noodles during their preparation exacerbates the adverse effects of refined grain on metabolic outcomes. In a cohort of older SingaporeanChinese, noodle consumption was found to be part of a dietary pattern comprising other less healthy food choices including red meats and deep-fried foods, which is associated with an increased risk of type 2 diabetes $^{(42)}$. In the present study, noodle consumption was found to be correlated with a higher intake of cholesterol, a lower intake of total fibre and vegetables and a lower PUFA:SFA ratio, suggesting that noodle consumption may serve as a marker of unhealthy dietary choices in this population. In the present study, rice consumption was found to be associated with a lower consumption of vegetables, but not with the consumption of other unfavourable food items. However, associations of both rice and noodle consumption with metabolic risk factors remained after adjustment for dietary risk factors.

It has been postulated that the adverse metabolic effects of high carbohydrate intakes on glucose and lipid metabolism are stronger in insulin-resistant individuals than in insulin-sensitive individuals ${ }^{(41)}$ and may thus be stronger in overweight individuals than in lean individuals ${ }^{(39)}$. In Asian populations, however, both stronger ${ }^{(10)}$ and weaker ${ }^{(11,43)}$ associations for glycaemic index, glycaemic load and high rice consumption have been observed for overweight individuals than for leaner individuals. In the present study, the association between rice consumption and HOMA-IR tended to be more pronounced among non-overweight participants, whereas the association between noodle consumption and HOMA-IR was more pronounced among overweight participants. Taken together, results regarding possible effect modification of the association between refined grain consumption and metabolic health outcomes by overweight status have not been consistent.

The specific biological mechanisms by which increased consumption of refined grains such as white rice and refined grain noodles may contribute to insulin resistance remain to be elucidated. Metabolic studies have shown that both the glycaemic index of foods and the amount of carbohydrates consumed contribute to the glycaemic response to a meal ${ }^{(40)}$. The glycaemic load reflects both the quality and quantity of carbohydrate intake. Commonly consumed rice varieties in this population such as Jasmine rice and glutinous rice typically have high glycaemic index values ${ }^{(44)}$. Data on the glycaemic index values of Asian types of noodles are limited. Published values are usually in the intermediate range (40-66 units, using glucose as a standard), although some types of noodles such as fresh wheat noodles have a high glycaemic index of $82^{(44,45)}$. Given the high carbohydrate content of both rice and noodles, their consumption can contribute to a higher dietary glycaemic load, which has been reported to be associated with a higher risk of type 2 diabetes in several ${ }^{(10,14-16)}$ but not in all $^{(23)}$ studies. Consumption of foods with a high glycaemic load leads to high postprandial glucose and insulin concentrations. The resulting peak in postprandial glucose concentrations is typically followed by a rapid decline in glucose concentrations, which may trigger the secretion of counter-regulatory hormones and reduce the suppression of circulating NEFA concentrations. Chronic elevations in postprandial concentrations of insulin, counter-regulatory hormones and NEFA may contribute to insulin resistance ${ }^{(20)}$.

Another possible explanation for the association between rice and noodle consumption and hyperglycaemia lies in the processing of the refined grains. This process removes most of the bran and some of the germ, resulting in the loss of various components that may be beneficial for glucose metabolism such as minerals, lignans and phenolic compounds ${ }^{(7)}$. Although we controlled for other dietary risk factors in the multivariable models in the present study, the possibility remains that high rice and noodle consumption contributes to metabolic disturbances by replacing foods that have a beneficial effect on glucose metabolism.

The strengths of the present study include the populationbased selection of participants, the reasonably large sample size, and the detailed information on dietary intakes and potential confounders based on validated questionnaires. However, the study also has several limitations. First, the cross-sectional nature of the study did not allow us to determine the direction of effects. However, we excluded individuals with known diabetes or CVD. It seems unlikely that the remaining participants were aware of their glycaemic blood markers and that the concentrations of these biomarkers affected food choices. Second, measurement error in the assessment of dietary intakes was inevitable. However, this is unlikely to explain the observed associations in the present study, as this would have weakened rather than strengthened the associations. We did not distinguish between whole-grain noodles and brown rice in our questionnaire. However, in the Singaporean population, as in most Asian populations ${ }^{(4,5)}$, consumption of brown rice and whole-grain noodles was rare at the time of the study. Our findings for rice consumption and metabolic risk factors can, therefore, be assumed to reflect associations for high white rice and refined grain noodle consumption. Finally, although we considered a wide range of potential confounders, residual confounding by unmeasured or imperfectly measured confounders may still have affected the results of the study.

In several cohort studies, high white rice consumption has been reported to be associated with a higher risk of type 2 diabetes. The results of the present study suggest that this association may be mediated by detrimental effects of high rice consumption on insulin sensitivity, rather than by the effects on systemic inflammation. We observed that high consumption of noodles may be at least as detrimental for metabolic risk factors as high consumption of white rice. Previous studies in Asian population have mainly focused on white rice, but attention on noodles, which are frequently consumed by many East Asian and South East Asian populations, is also warranted. If these detrimental effects of high white rice and noodle consumption on glucose metabolism are confirmed in further epidemiological studies and randomised trials, it could have major implications for Asian populations that have very high refined grain intakes and a rapidly increasing burden of type 2 diabetes $^{(1)}$. 


\section{Supplementary material}

To view supplementary material for this article, please visit http://dx.doi.org/10.1017/S0007114513003486

\section{Acknowledgements}

The authors gratefully acknowledge the Health Promotion Board, Singapore, for use of their FFQ and database for dietary intake analyses.

The present study was supported by grants from the Biomedical Research Council (grant 03/1/27/18/216) and National Medical Research Council (grants 0838/2004, 1111/2007 and CSI/0002/2005), Singapore. The funders had no role in the design and analysis of the study or in the writing of this article.

The authors' contributions are as follows: Y. L. M. Z. had the primary responsibility for writing the manuscript; S. A. R. contributed to the analytical design and revised and edited the manuscript; P. L. O. and H. Z. analysed the data and edited the manuscript; J. L. and E. S. T. collected the data; R. M. V. D. developed the analytical plan, interpreted the results, contributed to manuscript writing, reviewed the manuscript, and directed the study. All the authors read and approved the final version of the manuscript.

Y. L. M. Z., S. A. R., P. L. O., H. Z., J. L. and R. M. V. D. do not have any conflicts of interest. E. S. T. has served as a member of advisory panels for Astra Zeneca (S) Private Limited, Merck Sharp and Dohme Asia Pacific Services Private Limited, Novo Nordisk Pharma (S) Private Limited, Novartis (S) Private Limited, Unilever and Bristol-Myers Squibb (S). He has lectured at Bristol-Myers Squibb Singapore, Residual Risk Reduction Initiative, Astra Zeneca (S) Private Limited, Abbott Manufacturing, Singapore, MSD Technology Singapore and Glaxo Smith-Kline, Singapore.

\section{References}

1. Wild S, Roglic G, Green A, et al. (2004) Global prevalence of diabetes: estimates for the year 2000 and projections for 2030. Diabetes Care 27, 1047-1053.

2. Chang T-T (2000) Rice, Staple Foods: Domesticated Plants and Animals from The Cambridge World History of Food. Cambridge: Cambridge University Press. http:// www.cambridge.org/us/books/kiple/rice.htm (accessed September 2011).

3. Ahn Y, Park SJ, Kwack HK, et al. (2013) Rice-eating pattern and the risk of metabolic syndrome especially waist circumference in Korean Genome and Epidemiology Study (KoGES). BMC Public Health 13, 61.

4. Spiller GA (2002) Whole Grain, Whole Wheat and White Flours in History. St Paul, MN: Eagan Press.

5. Misra A, Rastogi K \& Joshi SR (2009) Whole grains and health: perspective for Asian Indians. J Assoc Physicians India 57, 155-162.

6. Ohnuki-Tierney E (1993) Rice as Self: Japanese Identities Through Time. Princeton, NJ: Princeton University Press.

7. Slavin JL, Martini MC, Jacobs DR, et al. (1999) Plausible mechanisms for the protectiveness of whole grains. $A m J$ Clin Nutr 70, 459S-463S.
8. Slavin JL, Jacobs D, Marquart L, et al. (2001) The role of whole grains in disease prevention. J Am Diet Assoc 101, $780-785$.

9. Sun Q, Spiegelman D, van Dam RM, et al. (2010) White rice, brown rice, and risk of type 2 diabetes in US men and women. Arch Intern Med 170, 961-969.

10. Villegas R, Liu S, Gao YT, et al. (2007) Prospective study of dietary carbohydrates, glycemic index, glycemic load, and incidence of type 2 diabetes mellitus in middle-aged Chinese women. Arch Intern Med 167, 2310-2316.

11. Nanri A, Mizoue T, Noda M, et al. (2010) Rice intake and type 2 diabetes in Japanese men and women: the Japan Public Health Center-based Prospective Study. Am J Clin Nutr 92, 1468-1477.

12. Hu EA, Pan A, Malik V, et al. (2012) White rice consumption and risk of type 2 diabetes: meta-analysis and systematic review. BMJ 344, e1454.

13. Jenkins DJ, Wolever TM, Taylor RH, et al. (1981) Glycemic index of foods: a physiological basis for carbohydrate exchange. Am J Clin Nutr 34, 362-366.

14. Salmeron J, Ascherio A, Rimm EB, et al. (1997) Dietary fiber, glycemic load, and risk of NIDDM in men. Diabetes Care 20 $545-550$

15. Salmeron J, Manson JE, Stampfer MJ, et al. (1997) Dietary fiber, glycemic load, and risk of non-insulin-dependent diabetes mellitus in women. JAMA 277, 472-477.

16. Liu S (2002) Intake of refined carbohydrates and whole grain foods in relation to risk of type 2 diabetes mellitus and coronary heart disease. J Am Coll Nutr 21, 298-306.

17. Halton TL, Liu S, Manson JE, et al. (2008) Low-carbohydratediet score and risk of type 2 diabetes in women. Am J Clin Nutr 87, 339-346.

18. Radhika G, Van Dam RM, Sudha V, et al. (2009) Refined grain consumption and the metabolic syndrome in urban Asian Indians (Chennai Urban Rural Epidemiology Study 57). Metabolism 58, 675-681.

19. Sluijs I, van der Schouw YT, van der AD, et al. (2010) Carbohydrate quantity and quality and risk of type 2 diabetes in the European Prospective Investigation into Cancer and Nutrition-Netherlands (EPIC-NL) study. Am J Clin Nutr 92, 905-911.

20. Ludwig DS (2002) The glycemic index: physiological mechanisms relating to obesity, diabetes, and cardiovascular disease. JAMA 287, 2414-2423.

21. Esfahani A, Wong JM, Mirrahimi A, et al. (2009) The glycemic index: physiological significance. J Am Coll Nutr 28, Suppl., 439S-445s

22. Liu S, Manson JE, Stampfer MJ, et al. (2000) A prospective study of whole-grain intake and risk of type 2 diabetes mellitus in US women. Am J Public Health 90, 1409-1415.

23. Meyer KA, Kushi LH, Jacobs DR, et al. (2000) Carbohydrates, dietary fiber, and incident type 2 diabetes in older women. Am J Clin Nutr 71, 921-930.

24. Fung TT, Hu FB, Pereira MA, et al. (2002) Whole-grain intake and the risk of type 2 diabetes: a prospective study in men. Am J Clin Nutr 76, 535-540.

25. Woo J, Ho SC, Sham A, et al. (2003) Diet and glucose tolerance in a Chinese population. Eur J Clin Nutr 57, 523-530.

26. Kim K, Yun SH, Choi BY, et al. (2008) Cross-sectional relationship between dietary carbohydrate, glycaemic index, glycaemic load and risk of the metabolic syndrome in a Korean population. BrJ Nutr 100, 576-584.

27. Mohan V, Radhika G, Sathya RM, et al. (2009) Dietary carbohydrates, glycaemic load, food groups and newly detected type 2 diabetes among urban Asian Indian population in 
Chennai, India (Chennai Urban Rural Epidemiology Study 59). Br J Nutr 102, 1498-1506.

28. Zhang G, Pan A, Zong G, et al. (2011) Substituting white rice with brown rice for 16 weeks does not substantially affect metabolic risk factors in middle-aged Chinese men and women with diabetes or a high risk for diabetes. $J$ Nutr 141, 1685-1690.

29. Li S, Shin HJ, Ding EL, et al. (2009) Adiponectin levels and risk of type 2 diabetes: a systematic review and metaanalysis. JAMA 302, 179-188.

30. Mineo C \& Shaul PW (2012) Novel biological functions of highdensity lipoprotein cholesterol. Circ Res 111, 1079-1090.

31. Yim-Lui Cheung C, Wong TY, Lamoureux EL, et al. (2010) C-reactive protein and retinal microvascular caliber in a multiethnic Asian population. Am J Epidemiol 171, 206-213.

32. Nang EE, Khoo CM, Tai ES, et al. (2009) Is there a clear threshold for fasting plasma glucose that differentiates between those with and without neuropathy and chronic kidney disease?: the Singapore Prospective Study Program. Am J Epidemiol 169, 1454-1462.

33. Nang EE, Gitau Ngunjiri SA, Wu Y, et al. (2011) Validity of the International Physical Activity Questionnaire and the Singapore Prospective Study Program physical activity questionnaire in a multiethnic urban Asian population. BMC Med Res Methodol 11, 141.

34. Deurenberg-Yap M, Li T, Tan WL, et al. (2001) Validation of a semiquantitative food frequency questionnaire for estimation of intakes of energy, fats and cholesterol among Singaporeans. Asia Pac J Clin Nutr 9, 282-288.

35. Matthews DR, Hosker JP, Rudenski AS, et al. (1985) Homeostasis model assessment: insulin resistance and beta-cell function from fasting plasma glucose and insulin concentrations in man. Diabetologia 28, 412-419.
36. Lopez-Garcia E, van Dam RM, Qi L, et al. (2006) Coffee consumption and markers of inflammation and endothelial dysfunction in healthy and diabetic women. Am J Clin Nutr 84, 888-893.

37. Expert WHO Consultation (2004) Appropriate body-mass index for Asian populations and its implications for policy and intervention strategies. Lancet 363, 157-163.

38. American Diabetes Association (2011) Diagnosis and classification of diabetes mellitus. Diabetes Care 34, Suppl. 1, S62-S69.

39. Jeppesen J, Schaaf P, Jones C, et al. (1997) Effects of low-fat, high-carbohydrate diets on risk factors for ischemic heart disease in postmenopausal women. Am J Clin Nutr 65, $1027-1033$.

40. Willett W, Manson J \& Liu S (2002) Glycemic index, glycemic load, and risk of type 2 diabetes. Am J Clin Nutr 76, 274 S-280S.

41. Murakami K, Sasaki S, Takahashi Y, et al. (2006) Dietary glycemic index and load in relation to metabolic risk factors in Japanese female farmers with traditional dietary habits. Am J Clin Nutr 83, 1161-1169.

42. Odegaard AO, Koh WP, Butler LM, et al. (2011) Dietary patterns and incident type 2 diabetes in chinese men and women: the Singapore Chinese Health Study. Diabetes Care 34, 880-885.

43. Sakurai M, Nakamura K, Miura K, et al. (2012) Dietary glycemic index and risk of type 2 diabetes mellitus in middle-aged Japanese men. Metabolism 61, 47-55.

44. Atkinson FS, Foster-Powell K \& Brand-Miller JC (2008) International tables of glycemic index and glycemic load values: 2008. Diabetes Care 31, 2281-2283.

45. Lok KY, Chan R, Chan D, et al. (2010) Glycaemic index and glycaemic load values of a selection of popular foods consumed in Hong Kong. BrJ Nutr 103, 556-560. 